\title{
Business Model Requirements and Challenges in the Mobile Telecommunication Sector
}

\author{
Mutaz M. Al-Debei \\ Brunel University, UB8, 3PH, London, UK. \\ School of Information Systems, Computing and Mathematics. \\ Mutaz.Al-Debei@brunel.ac.uk \\ David Avison \\ ESSEC Business School, Paris. \\ Avison@essec.fr
}

\begin{abstract}
The telecommunications business is undergoing a critical revolution, driven by innovative technologies, globalization, and deregulation. Cellular networks and telecommunications bring radical changes to the way telecom businesses are conducted. Globalization, on the other hand, is tearing down legacy barriers and forcing monopolistic national carriers to compete internationally. Moreover, the noticeable progress of many countries towards deregulation coupled with liberalization is significantly increasing telecom market power and allowing severe competition. The implications of this transition have changed the business rules of the telecom industry. In addition, entrants into the cellular industry have had severe difficulties due to inexistent or weak Business Models (BMs). Designing a BM for a mobile network operator is complex and requires multiple actors to balance different and often conflicting design requirements. Hence, there is a need to enhance operators' ability in determining what constitutes the most viable business model to meet their strategic objectives within this turbulent environment. In this paper, the authors identify the main mobile BM dimensions along with their interdependencies and further analysis provides mobile network operators with insights to improve their business models in this new 'boundary-less' landscape.
\end{abstract}

\section{Keywords}

Business Model, Mobile Network Operator, Business Model Requirements and Challenges, Technology, Information Systems. 


\section{Introduction}

The ability to communicate from anywhere at any time presents extraordinary levels of flexibility and expediency, and the stage is now clear for wireless networks and telecommunications to bring tremendous changes to the way businesses are conducted and the way in which we live our lives. Because of the newness of this area as well as the provisioning of new technologies such as third and fourth generation cellular phone services, this has become one of the most important and exciting areas for research purposes.

Most of the research into cellular technology so far has addressed the technical and engineering issues related to its infrastructure. For instance, Lin (1996) discusses mobility management, that is, how to track the locations of the users and allow user movement during conversations, Li and Chao (2004) investigate an analytical model for cellular communications networks, and Chaouchi et al. (2006) discuss certain issues related to signaling information in integrated $4 \mathrm{G}$ networks. Although the business model concept is becoming one of the important domains in the field of Information Systems (IS), few researchers have looked at the cellular technology domain from a business and information systems perspective, with the exception of marketing aspects (for example, Timmers, 1998; Weill and Vitale, 2001; Pateli and Giaglis, 2004) and less attention has been given to the business models of mobile network operators as discussed in this paper.

The mobile communications domain is witnessing increasing popular interest, including the business models of mobile network operators (MNOs) which is particularly important. Recent developments in cellular technologies (i.e. $3 \mathrm{G}$ and beyond) have generated new business models that might be adopted by different MNOs (Kim et al., 2006; Ballon, 2007). Mobility and ubiquity, two main aspects of pervasive computing, along with other cellular user requirements of novel data services such as web browsing, multimedia messaging (MMS) and global positioning systems (GPS), have significantly influenced the viability of the BMs by MNOs. Yet, MNOs are not exploiting these technological opportunities effectively. Further, entrants into the promising cellular telecom industry have been held back by inexistent or fragile BMs (Kallio et al. 2006). Designing business models for MNOs is a multifaceted process requiring multiple actors to balance different and often 
conflicting design requirements (Haaker et al., 2006). MNOs need to adapt as their strategies, business domains, and information systems change in a world of increasing environmental complexity. Enhancing their competitive positions by improving their ability to respond quickly to rapid environmental changes with high quality business decisions can be supported by appropriate business models.

The research discussed in this paper provides mobile network operators with insights to develop business models appropriate for this new 'boundary-less' landscape. We critically analyze the literature on mobile business models and identify the main BM dimensions along with their interdependencies. We also highlight the implications of telecommunications revolution on mobile business models.

The research question is formulated as follows:

What constitutes the most viable BM that meets various strategic objectives and goals for MNOs in a turbulent business environment?

In the next section, the major implications of the telecommunications revolution on the business of mobile network operators are discussed. There follows a contextual introduction to the mobile business model domain and the authors highlight the different viewpoints of researchers looking at the business models of technology companies in general. The paucity of research into the business model constituents of mobile network operators is revealed. The authors then offer a generic model based on value proposition, value architecture, value network and value finance. The environmental business issues and concerns affecting the feasibility of mobile business models are then examined. Based on this analysis, the authors are able to provide insights for further developing the business models of mobile network operators.

\section{A Revolution on the Move: The Implications on MNOs}

The telecommunications business is undergoing a major change, driven by innovative technologies, globalization, and deregulation coupled with liberalization. Recent 
technological leaps in cellular networks and telecommunications are bringing enormous changes to the way mobile businesses are conducted. This is much more apparent now that telecommunications is shifting from an industry that was all about voice, to one that is mostly about data (Dodourova, 2003). Cellular technology generations, particularly those starting from Global System for Mobile Communication (GSM) to 3G Universal Mobile Telecommunication System (UMTS) and beyond, are continuously enhancing the quality of such data services and offering new ones. The convergence of these technologies is enabling mobile users to communicate richer information in unprecedented levels of flexibility and convenience. Accordingly, new competencies now revolve around 'customers' and 'content', rather than 'technology infrastructure'.

At the same time, globalization is tearing down legacy telecom barriers and forcing monopolistic national carriers to compete globally. Moreover, the noticeable progress of many countries towards telecoms liberalization is significantly increasing market power leading to severe competition. The implications of this have changed the business rules of the telecom industry. For instance, cellular infrastructure deployment is no longer a major problem, but how to co-operate in a much more complex system (i.e. value network) to launch services efficiently and effectively is much more of a concern. Analyzing the telecom industry in terms of 'value chain' is no longer an appropriate or valid mechanism (Haaker et al., 2006; Peppard and Rylander, 2006; Bouwman and MacInnes, 2006; Ballon, 2007).

The structure of the telecom industry is shifting from an 'autocratic' state to a more 'democratic' one where a more complex and open system including extensive collaboration, communication, and co-ordination are the prevalent. In response, telecom companies have been compelled to overhaul their businesses and repackage themselves; that is, overhauling their business models. Some companies have accommodated mergers, acquisitions, and different types of strategic alliances to sustain their businesses. Companies adopting appropriate business models have seized opportunities associated with this technological revolution and enhanced their market positions. Mobile network operators are no exception. For instance, while O2 (formerly BTCellnet) and Vodafone are seen as the big players, they no longer dominate UK's mobile market (Olla and Patel, 2002; Ofcom, 2008). The success of 
NTT DoCoMo's i-mode in Japan has been credited to its innovative and well designed business model (Bouwman and MacInnes, 2006; Ballon, 2007).

We now provide a discussion of the business model concept in general, and then in the context of mobile network operators.

\section{Business Models in Context}

\subsection{What is a Business Model?}

Although many researchers and practitioners are interested in business models for technology companies, the answer to 'what is a business model?' is not straightforward. Definitions vary and the BM concept is sometimes confused with other business terms such as strategy and business process modeling.

In an attempt to distinguish between the business model and strategy business concepts, Magretta (2002: p.4) explained BMs as follows: "The business model tells a logical story explaining who your customers are, what they value, and how you will make money in providing them that value". In a more inclusive view that conceptualizes the business model as an intermediate layer between business strategy and ICT-enabled business processes, Camponovo and Pigneur (2003: p.4) describe the concept as "A detailed conceptualization of an enterprise's strategy at an abstract level, which serves as a base for the implementation of business processes". Further, the business model is sometimes misrepresented as a business case, for example to describe financial analysis processes, such as profit evaluation. For Instance, Linder and Cantrell (2000: p.2) argue that "The business model for profit-oriented enterprise explains how it makes money". It has also been used to depict coordination systems and cross-company collaboration. Haaker et al. (2004), to give just one example, define the BM concept as "a blueprint collaborative effort of multiple companies to offer joint proposition to their consumers".

As we have seen, the concept has been depicted from different perspectives, and some researchers have described the business model based on one or some of its components. Perhaps, this lack of agreement is due to the youthfulness of this concept, since it has risen to prominence only towards the end of $1990 \mathrm{~s}$ with the advent of IT-centered businesses (Hawkins, 2001; Stähler, 2002; Osterwalder et al., 
2005). However, to address this gap, (Al-Debei et al., 2008a) attempt to synthesize the literature. Through that synthesis, they define the BM concept as follows:

"The business model is an abstract representation of an organization, be it conceptual, textual, and/or graphical, of all core interrelated architectural, co-operational, and financial arrangements designed and developed by an organization presently and in the future, as well all core products and/or services the organization offers, or will offer, based on these arrangements that are needed to achieve its strategic goals and objectives".

The inclusion of 'strategic' in this definition indicates that the business model mainly serves the strategic level of different digital business organizations. In view of that, we agree with both Magretta (2002) and Camponovo and Pigneur (2003), that the BM is not a strategy, instead it represents an intermediate layer between business strategy and ICT-enabled business processes (see AL-Debei et al., 2008a,b). In other words, $\mathrm{BM}$ is a valuable layer needed to align and exemplify the relationships between information systems and business strategy (Hedman and Kalling, 2003).

\subsection{Cellular Business Model Constituents}

In the previous section we highlighted the different views of researchers looking at the business model of technology companies, and we presented a definition synthesizing those perspectives on the topic. In this section we discuss specifically the components of cellular business models.

Although some IS-related literature discusses business model structure, components, elements, and even ontologies (for example, Amit and Zott, 2001; Petrovic et al., 2001; Chesbrough and Rosenbloom, 2002; Pateli and Giaglis, 2003; Osterwalder et al., 2005; Gordijn et al., 2005), only a paucity addresses business model constituents in the mobile telecom sector. One exception is that of Camponovo and Pigneur (2003) who argue that the business model for telecoms consists of five main components: value proposition, target customers, business partners, core activities, and revenue flows. Although they adopt the Osterwalder and Pigneur (2002) framework, Camponovo and Pigneur (2003) provide only a very brief description of each BM 
component without drilling down into a detailed view. Their focus was more to give a general overview of the different actors participating in the mobile business.

Another example is that of Haaker, Bouwman and Faber who are participants of a broad research agenda that includes the Business4Users (B4U) project. Instead of focusing on a BM for a single organization within the cellular telecom industry, they provide a perspective on cross-company collaboration in complex value networks required for cellular services. Taking into account Haaker et al. (2004, 2006), Bouwman et al. $(2004,2005)$ and Faber et al. $(2003,2004)$, the cellular BM consists of service, technology, organization, and finance design components. Nevertheless, they did not discuss the value network, as a component of cellular BM, in their study since the BM was seen as a complex system of companies. Moreover, their study emphasized the marketing aspects of a few cellular data services, in particular, determining critical design factors of each design component of selected cellular data services. Further, some critical factors for cellular companies have been neglected in their study, including network coverage, capacity, reliability, and interoperability.

The exploratory research of Kallio et al. (2006) focused on the factors that are shaping the emerging market of cellular data services. They selected the external factors affecting mobile network operators' BMs using Osterwalder et al. (2002), but adopting Rajala et al.'s (2001) framework for selecting the BM internal factors. They replaced the revenue logic with the value creation component. The internal factors in their proposed framework are: product development strategy, sales and marketing strategy, servicing and implementation strategy, and value creation strategy. External factors are listed as: customer base, government policy and regulation, technological advances, and value chain dynamics between MNOs and suppliers. They use the adopted frameworks to compare five different cellular markets. Kallio et al. (2006) perceive the BM and strategy concepts as identical and so use them interchangeably.

Concerning the political economy of ICT services, Ballon (2007) provided an analytical framework in which he argued that the design of business models concern the configuration of control and value parameters. While control includes value network and functional architecture parameters, the value parameters include financial model and value proposition. However, the interdependencies among the proposed BM parameters were not discussed. 
Van de Kar et al. (2003) argue that the service formula (including customer value), enabling technology, network formation and coordination, and revenue model are the primary components of the mobile business model. However, they investigate the business model concept at the service level. Their focus was to understand the provisioning of the Radio538 ringtunes i-mode services through an interorganizational network of firms.

So far in this section we have shown a somewhat fuzzy and inconsistent understanding of business models for ICT driven companies which is even further evident for mobile network operators along with their services. However, the following four points summarize our literature analysis findings:

(1) Most of the cellular BM studies only list BM components with a general and brief description.

(2) These studies depict cellular BM components from different points of view and each concentrates on only a few parts of the whole. For instance, while Ballon (2007) investigated the cellular BM components from a political economy perspective, B4U project participants (e.g. Haaker et al., 2006) place an emphasis on cross-company collaboration.

(3) Researchers investigate the mobile business models at different levels. For example, while Van de kar et al. (2003) delineated the business model elements at a cellular service level (ringtunes i-mode), Kallio et al. (2006) addressed the mobile business model at an organizational level (MNO-level).

(4) Different researchers define the main components of mobile business models using different terminologies which, sometimes, are mystified with those used in strategy.

To address these issues by taking into consideration the different views into the business model constituents of mobile network operators, we introduce the $\mathrm{V}^{4}$ Business Model framework in the next section. We argue that this is more comprehensive and suitable for MNOs in this environment that is characterized by continuous rapid change. 


\section{The Dimensional Arrangements of Mobile Business Models}

In the previous section we established that there is a lack of consensus about the BM concept in general, and more specifically about the main constituents of mobile business models. We now introduce a generic business model framework (the $\mathrm{V}^{4}$ model) for mobile network operators based on Value proposition, Value network, Value architecture, and Value finance dimensions. The terminology used in this model suggests its nature as purely value-based. Only core arrangements are delineated within these four dimensions. Each aims to provide the market with desired values through the provision of services and products. The business model dimensions are also depicted in terms of value designates showing that these dimensional core arrangements add value to MNOs businesses.

It is important first to underline the main features that differentiate the BM of mobile network operators from those of other industries such as eCommerce (see points 1 and 2 below), and to highlight how even addressing the BM within a specific industry such as the telecom can itself differ (points 3 and 4) :

(1) Content, in terms of meanings (semantics) of the BM pillars along with their building blocks. For instance, while cellular technology generation and its associated infrastructure are considered part of MNOs' core assets/resources, a web server along with its associated hardware and software are the equivalent for Bricks-and-Clicks companies.

(2) The relative importance of these dimensions for different businesses/industries. For example, since mobile network operators belong to a tight value system and depend on it to acquire the needed resources, they emphasize their value network and architecture components, while a software house may place more emphasis on its value proposition and financial elements.

(3) The perspective from which we examine the $B M$ for different businesses/industries. This perspective (for example, marketing, actor, and/or strategic highly influences the way in which we model the relationships among the BM elements. 
(4) The unit of analysis. This concerns the level (for example service, department, organization) at which we address the BM dimensions affecting the inclusiveness and validity of the proposed model.

Our approach suggests that the business model of mobile network operators needs to be considered at the operator level, from which a more detailed departmental or even service BM could be identified. Although looking at the business model of one or few cellular services is useful, this approach is limited and does not necessarily reflect the MNO's overall business model. While we cannot assume that the business model is designed for a set of companies joined within a value system, as the business model of each player is different, the degree of consistency among their BMs is the key to their success (or failure).

\subsection{V $\mathrm{V}^{4}$ Business Model of MNOs}

We now introduce our $\mathrm{V}^{4}$ model for mobile network operators (see figure 1). We regard the business model of MNOs as core tactical arrangements enabling the achievement of their strategic goals and objectives. We now discuss our suggested four value dimensions of the mobile business model.

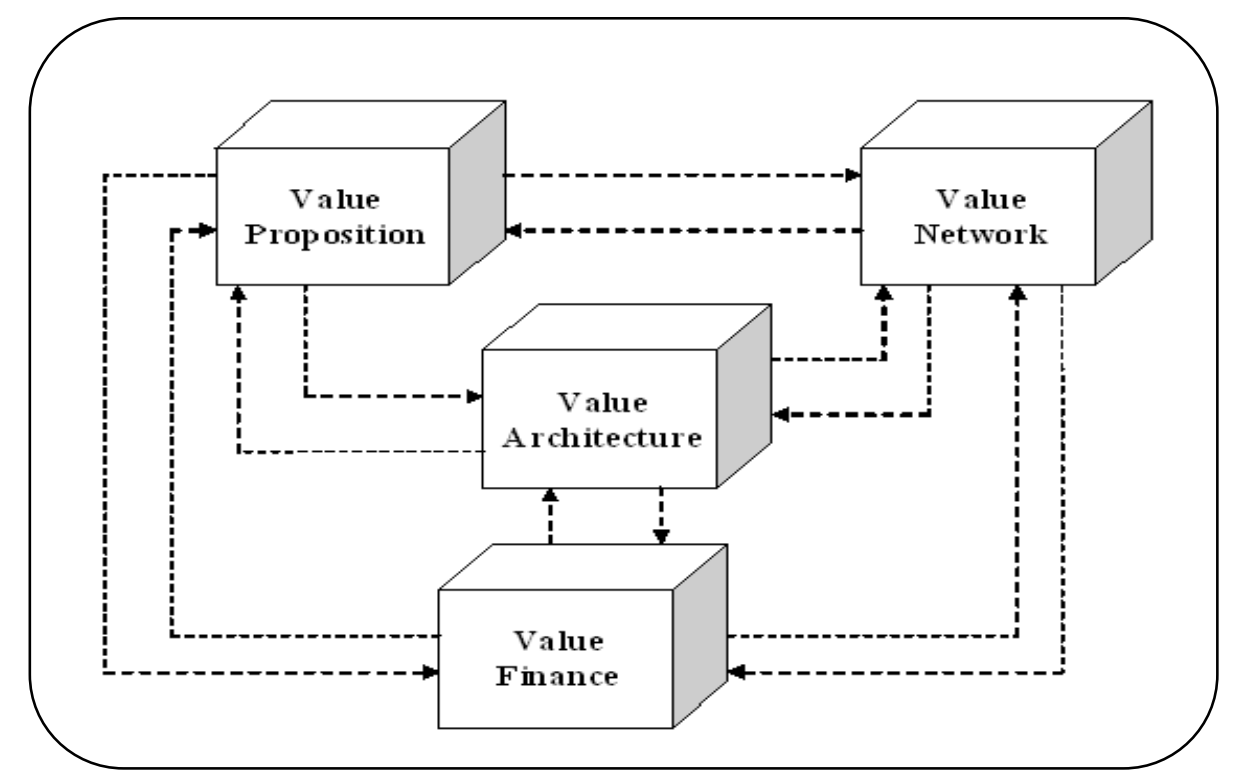

Figure 1. $V^{4}$ Mobile BM Dimensions 


\subsubsection{Value Proposition}

The value proposition dimension embraces descriptions about core services and products that the MNO offers, or will offer, along with their intended value elements. The nature of targeted individual and business customers along with their wants and needs are also included. Mobile network operators could focus on a niche or a mass market since targeting is about choosing profitable target clusters. The portfolio of customers could include:

(1) Different groups of individual customers classified according to their demographics, income, preferences, size of market or any other factors.

(2) Business customers (enterprises) that could be classified according to the size of business (small to large), or their business needs.

(3) Other mobile network operators signing agreements for 'roaming' service reasons.

(4) Mobile Virtual Network Operators for infrastructure usage reasons.

It is clear that the requirements of these heterogeneous customers are diverse and often conflicting, and this represents a challenge for MNOs since their wants are required to be balanced and addressed sensibly.

Cellular services could be categorized (Olla and Atkinson, 2004) into mobile entertainment systems (news, e-mail, chat, etc.), mobile messaging systems (SMS, EMS, and MMS), location-based information systems (GPS), mobile commerce systems (m-commerce and e-payment), and mobile data systems in addition to voice interactive cellular services. The main concern revolves around value creation, and there are many factors to establishing cellular value, such as time-critical arrangements, efficiency ambitions and those relating to on-the-road situations (Van de Kar et al., 2003).

Adding value depends on the ability of MNOs to provide customers with cellular services that meet their preferences and satisfy them (Kasper et al., 1999). For MNOs, adding value is a challenge and is essential to maximize the average revenue per user (ARPU) since cellular services and applications are what customers care about. However, within such a competitive industry where each MNO needs to enhance its 
strategic position and adding value exceeding those of its rivals is key, a malfunction occurs when the perceived value by users is less than the intended value by MNOs.

\subsubsection{Value Network}

The value network component represents the external arrangements which revolve around the communication and collaboration a MNO needs and conducts with other businesses in its value system, including suppliers, third parties, and intermediaries. This is crucial since delivering cellular services as desired requires a great deal of diversified resources that rarely exist within one MNO organization. In contrast with the traditional resource-based (RB) theory suggesting that 'core assets/resources' should be arranged internally within an organization (Porter 1985), the economic value of today's digital organization is determined by its ability to absorb ICT resources and align them with existing resources, then diffuse them in activities which should create value propositions at lower cost and/or higher quality than its MNO rivals (Hedman and Kalling 2003). A MNO is a part of a complex value system which is often depicted as a 'value web' or 'value network'. Representing MNO interrelationships with other telecom industry players as a linear value chain is no longer valid (Berkhout and van der Duin 2004). However, a MNO business model includes the representation of the complex interactions it develops and sustains with other players in the cellular telecom industry such as: engineering equipment vendors, IS/IT application vendors, cellular device manufacturers, content providers, content aggregators, payment gateways, and wireless internet service providers (WISPs). These relationships could take the form of strategic alliances, strategic partnerships or any IS/IT sourcing type such as insourcing and outsourcing.

Value network arrangements include constructing interfaces with its multi-type customers. In addition to physical communication channels including intermediaries, MNOs are exploiting the Internet and other associated technologies such as portals and customer relationship management (CRM) tools to develop valuable virtual communication mechanisms with their customers. Further, these communication channels are vital to collect and distribute information about and for customers to offer customized services. The number, types, customer reach capabilities, and the quality of communication channels a MNO builds and maintains with its customers are critical to its success. 


\subsubsection{Value Architecture}

This dimension is the central one on which other pillars depend on and revolve around. Value architecture is a broad plan that specifies:

(1) Technological (technical) architectures and arrangements that enable cellular communications to operate efficiently and effectively.

(2) Organizational arrangements of resources and capabilities including a MNO's structure, task force, management mindsets, and culture to enable cellular service provisioning as desired. 'Soft' issues related to a MNO internal culture are particularly challenging.

Arrangements in this dimension are mainly concerned with the core tangible and intangible resources (e.g. intellectual capital, experience, tacit knowledge) that a MNO is equipped with, either internally or from its value system, in order to be able to deliver the intended functionality.

In relation to MNOs, functionality could be explained in terms of provisioned service types along with their quality that are technically made possible via cellular network technologies (e.g. GSM, GPRS, EDGE), protocols (e.g. CDMA2000, TDMA), engineering infrastructure equipments (e.g. transceivers, base stations, mobile telephone switching office), IS/IT network management applications, and handset design and content. However, even though they may be considered together as a factor enabling new service development, if they are driven solely by technology they are unlikely to be successful in the market (Van de Kar et al. 2003). Nevertheless, if properly utilized and appropriately configured, a MNO could transform these assets and resources into valuable 'core capabilities' or 'core competencies' according to Prahalad and Hamel (1990), which constitute its main source of sustainable competitive advantage. However, we suggest that effective MNOs are those able to support applications with different service requirements as desired.

\subsubsection{Value Finance}

Arrangements in this dimension are concerned with revenue models, investment decisions, revenue sharing, cost effectiveness, net cash and return (Faber et al., 2004). These arrangements could be classified into three categories: 
(1) Total Cost of Ownership (TCO). TCO is the overall cost of MNO core arrangements needed to provide cellular services as intended. TCO not only includes the cost of tangible materials, but also the cost of development, support and maintenance as well as the cost of the essential collaboration a MNO conducts with other value network players. Although the one-time cost (e.g. equipment and applications) appears to represent the greater MNO's expenditure, the MNO running cost (maintenance and upgrade) most often exceeds the one-time cost over time.

(2) Pricing methods. Cellular services have to be financially viable to help MNOs achieve their goals . TCO as well as other factors such as competition level determine the prices of provisioned cellular products and services. However, a MNO pricing method may differ across different cellular products and services and customer categories. Further, it may also differ over time according to the age of the MNO.

(3) Revenue structure. The generated revenue depends largely on the arrangements made concerning cost and pricing. The sources of revenue could be categorized based on customer types, cellular product and service type, or based on a combination of these. Cost and revenue distributions among different stakeholders should be also made explicit.

In sum, arrangements in this domain are related to those of all other dimensions. Thus, efficient propositional, architectural, and co-operational arrangements could positively influence the generated revenue of MNOs.

\subsection{The Interdependencies among Mobile Business Model Dimensions}

Engineering a BM for MNOs is a complex undertaking. Interdependencies and interrelationships are presented among the BM dimensions (see figure 2). In relation to MNOs, what is financially viable may not be viable for value proposition purposes, or may be difficult to configure and maintain, or even may be hard to acquire through the MNO's value network. Thus, a holistic alignment and a coherent trade-off among BM components are highly recommended. 


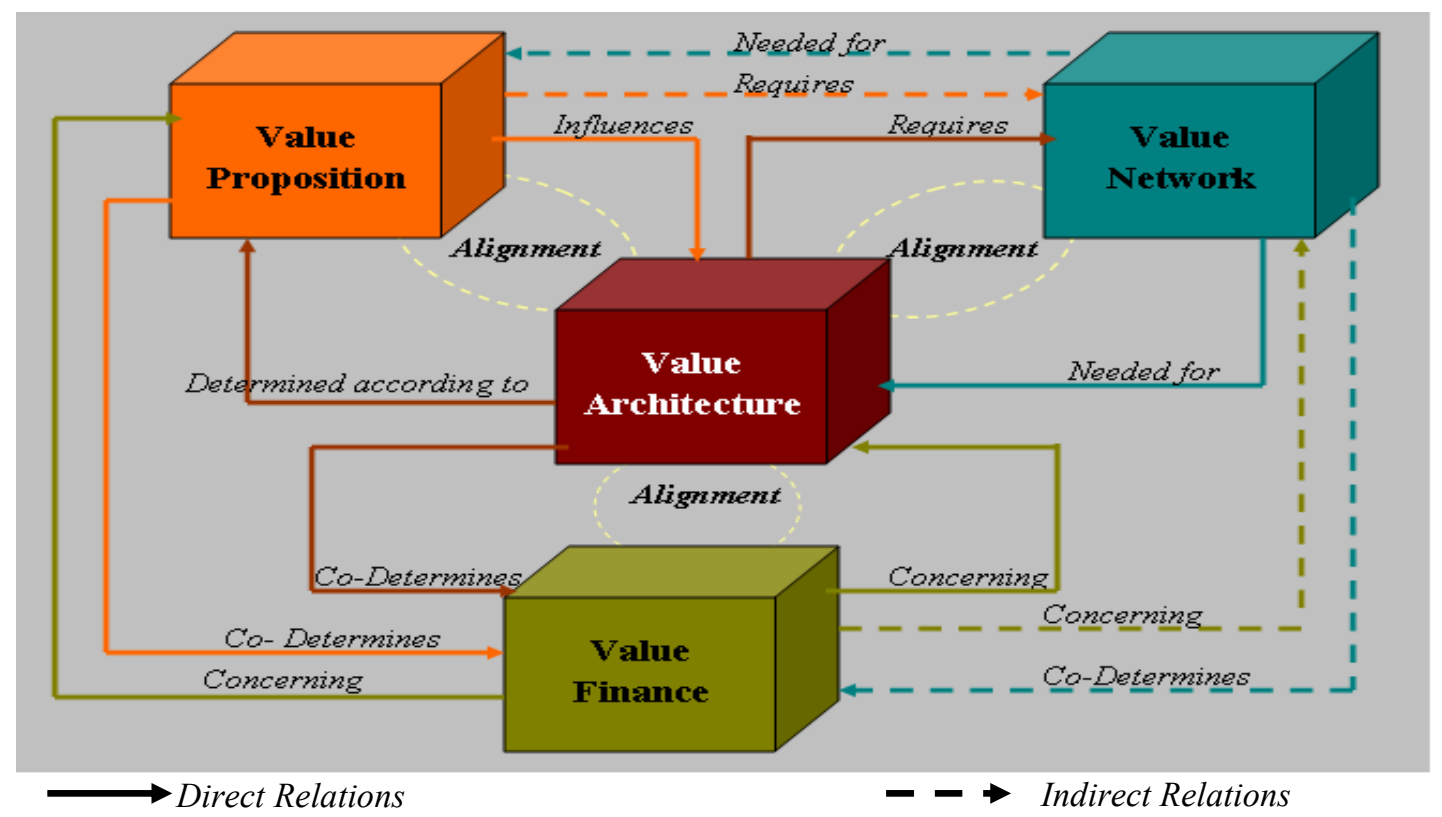

Figure 2. Interdependencies among Mobile BM Dimensions

The definition of the target customers along with their preferences represents the first step in a cellular BM engineering process. Given that, MNOs carry out external environment scanning processes seeking to properly identify profitable customer segment(s). Success, however, is most likely achieved when the offering is aligned with the preferences of cellular users. For good performance, the provisioned cellular products and services along with their characteristics have to match the wants and needs of MNO customers. Nonetheless, offering what is valued by MNO customers in the value proposition dimension requires an adequate and well configured technological infrastructure (see table 1).

To give a general overview, the first generation (1G) of cellular technology can only provide the best voice cellular service. The second generation $(2 \mathrm{G})$ is a digital cellular technology that not only enhances the cellular network capacity in general, but also introduced text messaging (SMS) as the first data service in cellular technology. This major shift from voice-centered to a data-centered cellular telecom industry has been enriched by the introduction of $2.5 \mathrm{G}$ cellular technology which is an 'always-on' technology that adds valuable data services such as web browsing, location-based services, and audio/video downloading. The delivery of voice and advanced data services coupled with high speed has been introduced by the third 
generation $(3 \mathrm{G})$ cellular technology. $4 \mathrm{G}$ is an IP-based integrated system capable of providing premium speed, quality, and security.

Table 1. MNOs Value Architecture and Value Proposition Correlation

\begin{tabular}{|c|c|c|}
\hline $\begin{array}{c}\text { Mobile } \\
\text { Tech. } \\
\text { Generation }\end{array}$ & $\begin{array}{l}\text { Representative } \\
\text { Products }\end{array}$ & $\begin{array}{c}\text { Value proposition } \\
\text { Characteristics and Quality }\end{array}$ \\
\hline $\begin{array}{l}\text { First } \\
\text { Generation } \\
(\mathbf{1 G})-\mathbf{1 9 8 0}\end{array}$ & $\begin{array}{l}\text { Total Access } \\
\text { Communication System } \\
\text { (TACS) - Europe } \\
\text { - Nordic Mobile Telephone } \\
\text { (NMT) system - Europe } \\
\text { - Advanced Mobile Phone } \\
\text { System (AMPS)- USA }\end{array}$ & $\begin{array}{l}\text { - Voice analogue telephony } \\
\text { - Paging } \\
\text { - Low level of security } \\
\text { - Limited Capacity }\end{array}$ \\
\hline $\begin{array}{l}\text { Second } \\
\text { Generation } \\
(2 G)-1990\end{array}$ & 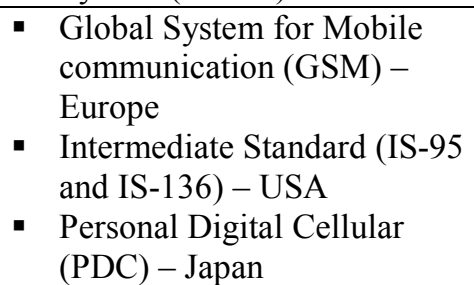 & $\begin{array}{l}\text { - Voice digital telephony } \\
\text { - Roaming } \\
\text { - Call forwarding } \\
\text { - Short Messaging Service (SMS) - } 160 \text { char } \\
\text { - Low data rate }\end{array}$ \\
\hline $\begin{array}{l}2.5 G \sim 2.75 G \\
-1996\end{array}$ & $\begin{array}{l}\text { - General Packet Radio } \\
\text { Service (GPRS) - Stage } 1 \\
(2.5 \mathrm{G}) \\
\text { - } \\
\text { Enhanced Data Rate for } \\
\text { GSM Evolution (EDGE) - } \\
\text { Stage } 2(2.75 \mathrm{G})\end{array}$ & $\begin{array}{l}\text { - } \text { Multimedia Messaging Service (MMS) } \\
\text { - Enhanced Messaging Service (EMS) - simple } \\
\text { media } \\
\text { - Location-based services } \\
\text { - Access to Internet (Web browsing) } \\
\text { - Higher data rate }\end{array}$ \\
\hline $\begin{array}{l}\text { Third } \\
\text { Generation } \\
(3 G)-2002\end{array}$ & $\begin{array}{l}\text { Universal Mobile } \\
\text { Telecommunication System } \\
\text { (UMTS) }\end{array}$ & $\begin{array}{l}\text { - Virtual Home Environment (VHE) feature } \\
\text { - Video on demand } \\
\text { - High speed } \\
\text { - Video calls and chat } \\
\text { - Mobile TV } \\
\text { - Broadband wireless data } \\
\text { - High speed internet access }\end{array}$ \\
\hline $\begin{array}{l}\text { Fourth } \\
\text { Generation } \\
\text { (4G, beyond } \\
3 G)-2012- \\
2015 \\
\text { (Proposed) }\end{array}$ & $\begin{array}{l}\text { Worldwide Interoperability } \\
\text { for Microwave Access } \\
\text { (WiMax) - Trials }\end{array}$ & $\begin{array}{l}\text { - } \text { Premium quality } \\
\text { - High security } \\
\text { - Premium Speed } \\
\text { - } \text { Digital Video Broadcasting (DVB) } \\
\text { - Interoperability with existing wireless } \\
\text { standards }\end{array}$ \\
\hline
\end{tabular}

The adopted cellular technology not only affects the provisioned cellular service types and quality, but also determines the infrastructure deployment in terms of number, type, and configuration of the technological arrangements such as transceivers, network management applications, and base stations. The cellular network's cellsites and their associated transceivers, to give just one example, differ in terms of number, 
type, functionality and cost across different generations of cellular technologies. This in turn, impacts the arrangements in the value network and value finance dimensions.

It is worth mentioning here that the complexity of value network enlarges with each fundamental technological advance. These leaps in technology enable provisioning of new services by MNOs which most likely require establishing further collaboration, communication, and co-operation. Such collaboration amongst value network businesses is essential to acquire assets, resources, and/or complementary services needed for value proposition purposes. However, MNOs providing advanced data services cooperate mainly with:

\section{(1) Hardware Vendors}

- Cellular device manufacturers to acquire the physical cellular devices such as cellular phones and personal digital assistants (PDAs).

- Network engineering equipment vendors to acquire the physical cellular network and telecommunication infrastructure such as transceivers and backbone switches and routers.

\section{(2) Software, Content, and Application Providers}

- Network engineering application vendors to acquire the soft infrastructure such as network and telecommunication management, control, network diagnostic, and optimization systems.

- Middleware (software interfaces) required to enable software running over MNOs' hardware for technical management and users' usage purposes. For example, software interfaces are needed to technically manage different switches and routers; remote access applications are required to maintain distant infrastructure; and operating systems could be required to be installed on handsets for content transmission and application-run reasons.

- Content providers to acquire needed information to be communicated to cellular customers.

- Content Aggregator to synthesize and fuse the provided content information which includes "customization-to-fit" process. 


\section{(3) Third Parties and Payment Gateways}

- Payment Gateways when mobile commerce is offered, payments gateways represent an intermediary (third party) which provides different methods of payments to cellular users.

- Billing Services. Mobile network operators frequently rely on a third party to manage the billing services.

\section{(4) Network and Service Providers}

- Wireless Internet Service Providers provide Internet accessibility to cellular customers.

- Other Mobile Network Operators provide additional services to their customers such as roaming.

- Mobile Virtual Network Operators buying or (leasing) network capacity which is then utilized to provide services under their own brand names.

Reasons underlying this collaborative effort could be classified into two broad categories:

(1) Elective reasons. These include cost reduction, exploitation of external advanced technologies, and reduced capital investment.

(2) Compulsory reasons. These include the rarity of needed technological resources, patent, and the existence of technological fabrication secrets (Camponovo and Pigneur, 2003).

The achievement of the intended benefits behind these collaborations is not straightforward. High levels of consistency among the BMs of value network players are essential to the economic value of each and are major drivers of their success. Moreover, a synergy between MNO's internal resources and assets with those acquired from its value network is necessary to create value capabilities and competencies needed for value proposition purposes. 


\section{Issues and Concerns of Mobile Business Models}

Due to the present enlarged competitive environment which is most apparent in the telecom industry, there are many external factors (see figure 3), discussed below, affecting the digital business models of mobile network operators.

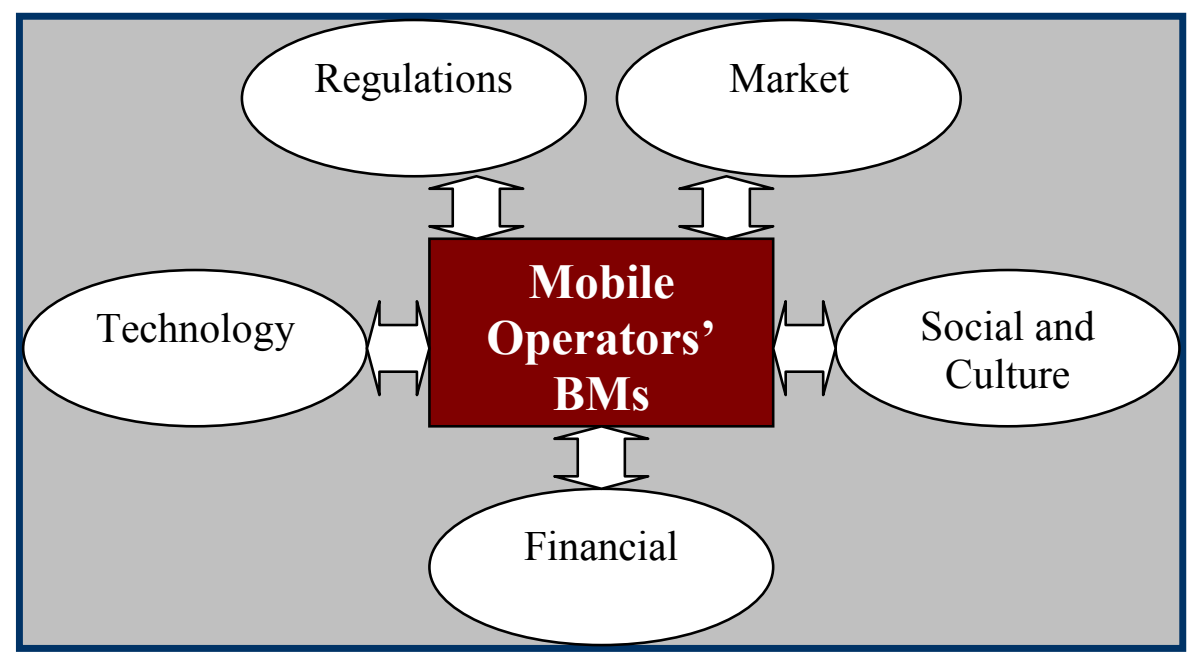

Figure 3. Environmental Concerns

\section{(1) Market Competitive Factors}

Along with the implications of the telecommunication revolution on the internationalization of market boundaries, the recent issues associated with liberalization, privatization, and deregulation have critically transformed the telecom market. The hallmark of these changes is the harsh competition among different mobile operators. The competition space is becoming more difficult to define due to blurred market boundaries. Nevertheless, the level of competition depends on the number of operators competing in the market, and the nature of the market structure as well.

Bouwman and MacInnes (2006) argue that market competitive factors are the most prominent in prompting ongoing opportunities for the innovation and development of products and services offered by MNOs. But the harsh business environment of telecoms has led to competition based principally on price (Maitland et al., 2002; Peppard and Rylander, 2006). This implies that MNOs are reducing their profit margins to be competitive. Consequently only a few MNOs can afford the budget required for Research and Development. 
Grundstrom and Wilkinson (2004) argue that while MNOs were the main drivers behind the development of standards for $2 \mathrm{G}$ systems, system manufacturers are pushing for the establishment of standards for $3 \mathrm{G}$ systems. They also attribute this to the increasing deregulation in telecommunication markets, and argued that its consequences are apparent.

Moreover, with growth in the telecom market (Barnes, 2002); barriers to entry are increasing in some countries such as the UK, resulting in a forceful competitive environment. Such barriers are having a negative impact on innovation in product developments of the mobile sector (Olla and Patel, 2002).

Coping with this highly competitive environment, operators hold on to their positional niche, establish and widen their customer base, and create value based on customer preferences since the customer base (individual users, businesses, MVNOs, and other MNOs) appears to be the most viable resource of revenue for telecom operators. Such severe competition allows cellular users to get quality service with competitive prices, whilst also significantly reduce the generated profits of MNOs.

\section{(2) Financial Factors}

In addition to the cost of maintaining the cellular network which is evolving over time, the cost of establishing a mobile network operator business represents a huge investment. Building up complete cellular networks and telecommunications is a major sunk cost to be paid back over a period of time by the generated revenues. Spectrum licenses represent another main source of cost, being so scarce. In Europe, most licensed $3 \mathrm{G}$ operators are not independent, but subsidiaries of larger telecommunication organizations (Maitland et al., 2002), and were thus more able to afford the $3 \mathrm{G}$ UMTS license. Acquiring the licenses for operating the $3 \mathrm{G}$ networks and beyond is another sunk cost (Olla and Patel, 2002) .

The force of competition requires MNOs to be innovative and sufficient budgets need to be allocated to $R \& D$ departments. The costs of furnishing debt can also be substantial due to the expansion strategies of mobile operators (Maitland et al., 2002). The costs of acquiring customers are also high (Peppard and Rylander, 2006). However, despite all these costs, MNOs need positive return on investments (ROI). 


\section{(3) Cellular and Disruptive Technologies Factors}

Wireless communication could be defined as the process of communicating information (e.g. voice, text, images) in electromagnetic media over a distance through the free-space environment (radio frequency transmission), rather than through traditional wired or other physical conduits (Pelton, 1995; Aungst and Wilson, 2005). In view of that, cellular value configuration is a complex process; since much less control is available over the transmission path. Given that the cellular communication is a radio frequency (RF) transmission, broadcasted signals are susceptible to many unpredictable conditions that interfere with reception, and may then lead to propagation problems such as shadow zones, rapid attenuation, multi-path interference, electromagnetic interference, and frequency-dependent propagation problems (Panko, 2005).

Mobile operators assume that $3 \mathrm{G}$ services and beyond will provide much of their revenue growth. However, the emergence of disruptive technologies such as ad hoc and self organized networks (WLANs) present only one threat to cellular technologies (Camponovo and Pigneur, 2003). These disruptive networks could utilize the 802.11 hot spots (Wi-Fi), which are access points offering Internet access in public places and have the potential to cover the globe. While WLAN offers speed up to around $70 \mathrm{Mbps}$ - much higher than $3 \mathrm{G}$ systems offer -, the latter offers more capacity. We suggest that $3 \mathrm{G}$ and other wireless technologies such as WLAN will be treated as complementary, rather than competitive. Moreover, we assume that 'privacy' and 'security' issues will be differentiators giving advantage to one over another.

\section{(4) Regulatory Factors}

Broadly speaking, the role of regulatory factors in shaping the structure of the telecom industry has been significantly increasing (Maitland et al., 2002). Deregulation and internationalization have radically changed the European telecom industry (Peppard and Rylander, 2006). Further, price regulations such as those related to interconnection charges and retail prices affect telecoms' profits. Internationally, regulation could play a bi-directional role. For example, liberalization enables market expansion and competition, while strict entry regulations could lead to market dominance. 
Governmental policies, regulations (and deregulations), and competition rules usually aim to reduce market dominance and ensure an evolution of a self sustaining competitive market structure, in which operators act in a competitive manner. Kallio et al. (2006) argue that markets that have had governmental support have taken off quickly relative to those that have not. Such support includes infrastructure investment, regulatory policies, education of its citizens, maintenance of customer prices at reasonable levels, policies that support fragmentation in an industry that rewards economies of scale, and the promotion of pricing transparency among consumers.

\section{(5) Social and Cultural Factors}

Technology is shaped by its social context. It is crucial to develop technologies that are 'social, culture, and user friendly'. It is most likely that cellular customers will reject any technology that violates health, social norms and values, culture, privacy, and/or ease of use. For example, health concerns may force mobile operators within a market to share a single infrastructure or reduce the number of deployed base stations (Camponovo and Pigneur, 2003). The consequences on mobile network operators can be major. Sharing infrastructure reducing capacity, while shrinking the number of base stations might reduce coverage. Cultural norms and values may prohibit the use of cameras embedded within mobile handsets in some countries, which affects the diffusion of those handsets.

\section{Conclusion: Towards Mobile Business model Optimization}

In this paper we have attempted to provide a more inclusive view of the business model of mobile network operators. We have also discussed some implications of the telecom revolution. Based on this analysis, we suggest that making the business model more explicit, dynamic, and open is fundamental. Explicit business models (textual and/or graphical) facilitate knowledge sharing and dissemination, and support operators in analyzing and evaluating the feasibility of their business models in action. Further, business models need to be flexible in this turbulent and highly competitive industry. Open business models also allow ideas to come from any stakeholder and enrich the value network, enabling the innovation that is required for value creation (Chesbrough, 2006). However, this requires open management mindsets and an appropriate internal culture. 
There is no direct proportional relationship between the technological excellence of the provisioned cellular services and operators' outcomes. This is because such a relationship is mediated by social context as the importance of social and cultural factors is significantly increasing due to the regional and international expansion strategies adopted by many operators. The variability of environmental factors such as customer-base size and nature, market opportunities, competition level, laws and regulations, and technological advances also affect MNO's business model viability and value. To give just one example, NTT DoCoMo's i-mode is a successful BM in Japan that had more varied results in the European market (Kallio et al. 2006).

It is also significant that services are delivered in a flexible and dynamic manner to the heterogeneous customers of MNOs while achieving quality of service (QoS) measures. The QoS parameters, such as transmission speed of services, their availability, usability, precision, coverage and reliability, along with security and privacy, are crucial to any MNO. Furthermore, providing these quality services within an MNO's network and maintaining them when customers access another cellular network, a public switched telephone network (PSTN), or the Internet is advantageous. Since a cellular service is only valuable if it fulfils customer needs or solves business problems, only those specific cellular services that add value to the targeted customers might be considered as candidates.

Concerning financial decisions, it is necessary to take into account the economic and financial viability of cellular services since offering affordable cellular products and services affects MNO's economic value and maximizes the achievement of goals and objectives. In addition to the subscription fees, a decision between transaction-based, volume-based, time-based, and revenue sharing pricing methods is needed.

On the other hand, technological factors in the value architecture dimension such as cellular network coverage, capacity, latency, congestion rate, scalability and flexibility, interoperability and compatibility, security, and network reliability substantially affect the quality of provisioned services. Subsequently, they influence MNOs' performance and their competitive positions. Therefore, a coherent trade-off between security issues and performance measures is recommended.

For outstanding performance, a MNO value network needs to encompass only players enabling the MNO to provide cellular services in better quality and lower prices than 
its rivals. When a MNO faces a decision of which value network players to cooperate with in order to acquire needed resources, it faces an unstructured decision of choosing one best suitable alternative. Offerings may be different in terms of resource types, service quality, and prices. Structured techniques, such as analytical hierarchy processing (AHP) provide rational and comprehensive frameworks for evaluating alternative solutions would be useful. Moreover, we suppose that MNOs are in strategic position within the telecom value network. MNOs need to lead the innovation process and manage it through value network actors. An MNO needs to allocate sufficient budget to $R \& D$, but this should be reflected in the agreed revenue share.

The bottom line is that optimizing the business model of mobile network operators requires a holistic configuration of its interrelated dimensions and harmonization with the operator strategy and its ICT-enabled business processes including IS, in addition to alignment with the external environmental concerns in general, and more specifically with industry forces.

\section{Acknowledgement}

The authors would like to thank Mrs. Enas Al-Lozi for her assistance, which in a way or another made this publication possible.

\section{References}

Al-Debei, M. M., El-Haddadeh, R., and Avison, D. (2008a) Defining the Business Model in the New World of Digital Business," In Proceedings of the 14th Americas Conference on Information Systems, AMCIS'08, Toronto, Canada, pp. 1-11.

Al-Debei, M. M., El-Haddadeh, R., and Avison, D. (2008b) Towards a Business Model for Cellular Networks and Telecommunication Operators: a Theoretical Framework," In Proceedings of the 13th Conference of the UK Academy for Information Systems, UKAIS'08, Bournemouth, UK, pp. 1-15.

Amit, R., and Zott, C. (2001) Value Creation in eBusiness. Strategic Management Journal, 6-7(22), pp. 493-520.

Aungst, S., Wilson, D. (2005) A primer for navigating the shoals of applying wireless technology to marketing problems. Journal of Business and Industrial Marketing, 20(2), pp. 59-69.

Ballon, P. (2007) Business Modelling Revisited: The Configuration of Control and Value. Info: The Journal of Policy, Regulation and Strategy for Telecommunications, 9(5), pp. 6-19. 
Barnes, S.J. (2002) The Mobile Commerce Value Chain: Analysis and Future Developments. International Journal of Information Management, 22(2), pp. 91-108.

Berkhout, G., and van der Duin, P. (2004). Mobile Data Innovation: Lucio and the Cyclic Innovation Model. In Proceedings of the sixth International Conference on Electronic Commerce, Delft, The Netherlands, 603-608.

Bouwman, H., Faber, E., and Haaker, T. (2004) Balancing strategic interests for network value of mobile services. Proceedings of the Tenth Americas Conference on Information Systems, New York, pp. 2521-2529.

Bouwman, H., Haaker, T., and Faber, E. (2005) Developing Mobile Services: Balancing Customer and Network Value. Proceedings of the 2005 second IEEE International Workshop on Mobile Commerce and Services, WMCS'05, PP. 21-31.

Bouwman, H., and MacInnes, I. (2006) Dynamic Business Model Framework for Value Webs. In Proceedings of the $39^{\text {th }}$ Hawaii International Conference on System Sciences, Hawaii, pp. 1-10.

Campanovo, G., and Pigneur, Y. (2003) Business model analysis applied to mobile business. Proceedings of the 5th International Conference on Enterprise Information Systems, Angers, April 23-26.

Chaouchi, H., Armuelles, I., Ganchev, I., O’Droma, M., and Kubinidze, N. (2006) Signalling Analysis in integrated 4G Networks. International Journal of Network Management, 16(1), pp. 59-78.

Chesbrough, H.W., and Rosenbloom, R. S. (2002) The Role of The Business Model in capturing value from innovation: evidence from Xerox Corporation's technology spin-off companies. Industrial and Corporate Change, 11(3), pp. 529-555.

Chesbrough, H.W. (2006) Open Business Models: How to Thrive in the New Innovation Landscape. Harvard Business School press, Boston.

Dodourova, M. (2003) Industry dynamics and strategic positioning in the wireless telecommunications industry: the case of Vodafone Group plc. Management Decision, 41(9), pp. 859-870.

Faber E., and Bouwman, H. (2003) Designing Business Models for Mobile Services. In proceedings of the 3rd International Conference on Electronic Business, ICEB, Singapore.

Faber, E., Haaker, T., and Bouwman, H. (2004) Balancing requirements for customer value of mobile services. Proceedings of the $17^{\text {th }}$ Bled eCommerce Conference on eGlobal, Bled, Slovenia.

Gordijn, J., Osterwalder, A., and Pigneur, Y. (2005) Comparing two business model ontologies for designing e-Business models and value constellations. In Proceedings of the 18th eConference of eIntegration in Action, Bled, Slovenia, pp. 1-17.

Grundstrom, C., Wilkinson, I. (2004) The role of personal networks in the development of industry standards: a case study of 3G mobile telephony. Journal of Business and Industrial Marketing, 19(4), pp. 283-293.

Haaker, T., Faber, E., and Bouwman, H. (2004) Balancing strategic interests and technological requirements for mobile services. Proceedings of 6th International Conference on E-commerce, ICEC04, Delft, The Netherlands. 
Haaker, T., Faber, E., and Bouwman, H. (2006) Balancing customer and network value in business models for mobile services. International Journal of Mobile Communication, 4(6), 645-661.

Hawkins, R. (2001) The Business Model as a Research Problem in Electronic Commerce. Star (socio-economic trends assessment for the digital revolution) IST Project, issue report no. 4, July 2001, SPRU- Science and Technology Policy Research.

Hedman, J., and Kalling, T. (2003) The Business Model Concept: Theoretical underpinnings and empirical illustrations. European Journal of Information Systems 12(1), pp. 49-59.

Kallio, J., Tinnila, M., and Tseng, A. (2006) An international comparison of operatordriven business models. Business Process Management Journal, 12(3), pp. 281-298.

Kasper, J. D. P., van Helsdingen, P. J. C., and de Vries jr. W. (1999) Service Marketing Management: An International Perspective, John Wiley and Sons Ltd, England.

Kim, C., Lee, H., and Park, Y. (2006) A Taxonomical Classification of Business Models on Mobile Business: Patent Analysis and SOM Mapping. IEEE International conference on Management of Innovation and Technology, 1(1), pp. 478-482.

Li, W., and Chao, X. (2004) Modeling and Performance Evaluation of a Cellular Mobile Network. IEEE/ACM Transactions on Networking (TON), 12(1), pp. 131-145.

Lin, Y. B. (1996) Mobility Management for Cellular Telephony Networks. IEEE Computer Security, 4(4), pp. 65-73.

Linder, J., and Cantrell, S. (2000) Changing Business Models: Surveying the Landscape. Accenture Institute for Strategic Change.

Magretta, J. (2002) Why Business Models Matter. Harvard Business Review, 80(5), pp. 86-92.

Maitland, C.F., Bauer, J.M., and Westerveld, R. (2002) The European Market for Mobile Data: Evolving Value Chains and Industry Structures. Telecommunications Policy, 26(9-10), pp. 485-504.

Ofcom (2008) The Communications 2008 (http://www.ofcom.org.uk/research/cm/cmr08/: accessed $5^{\text {th }}$ of November, 2008).

Olla, P., Atkinson, C. (2004), Developing a wireless reference model for interpreting complexity in wireless projects. Industrial Management and Data Systems, 104(3), pp. 262-272.

Olla, P., and Patel, N. (2002) A Value Chain Model for Mobile Data Service Providers. Telecommunications Policy, 26(9-10), pp. 551-571.

Osterwalder, A., and Pigneur, Y. (2002). An e-Business Model Ontology for Modeling e-Business. In the proceedings of the 15th Bled electronic commerce conference, Bled, Slovenia.

Osterwalder, A., Pigneur, Y., and Tucci, C.L. (2005) Clarifying Business Models: Origins, Present, and Future of the Concept. Communications of the Association of Information Systems, 15(May), pp. 2-40. 
Panko, R. (2005) Business Data Networks and Telecommunications. Fifth Edition, Prentice-Hall, Pearson Education, Inc., New Jersey, NJ.

Pateli, A. G., and Giaglis, G. M. (2003) A framework for understanding and analyzing ebusiness models. In Proceedings of 16th Bled eCommerce Conference on eTransformation, Bled, Slovenia, pp. 329-348.

Pateli, A. G., and Giaglis, G. M. (2004) A research framework for analyzing eBusiness models. European Journal of Information Systems, 13(4), pp. 302-314.

Peppard, J., and Rylander, A. (2006) From Value Chain to Value Network: Insights for Mobile Operators. European Management Journal, 24(2), pp. 1-22.

Petrovic, O., Kittl, C., and Teksten, D. (2001) Developing Business Models for eBusiness. In Proceedings of the International conference on Electronic Commerce.

Porter, M. E. (1985) Competitive Advantage: Creating and Sustaining Superior Performance. New York, NY.

Prahalad, C. K., and Hamel, G. (1990) The Core Competencies of the Corporation. Harvard Business Review, 68 (3), 79-91.

Rajala, R., Rossi, M., Tuunainen, V. K., and Korri, S. (2001) Software Business Models: a framework for analyzing the software industry. Technology Review, TEKES.

Stähler, P. (2002) Business Models as a unit of analysis for strategizing. Proceedings of $1^{\text {st }}$ International Workshop on Business Models, Lausanne, Switzerland.

Timmers, P. (1998) Business Models for Electronic Markets. Journal on Electronic Markets, 8(2), pp. 3-8.

Van de kar, E., Maitland, C., Wehn de Montalvo, U., and Bouwman, H. (2003) Design Guidelines for Mobile Information and Entertainment Services based on the Radio538 ringtunes i-mode service case study. In Proceedings of the 5th International Conference on Electronic Commerce, Pittsburgh, Pennsylvania, pp. 413-421.

Weill, P., and Vitale, M.R. (2001) Place to Space. Harvard Business School Press, Boston. 